\title{
One-Step Method for Preparation of Magnetic Nanoparticles Coated with Chitosan
}

\author{
Karla M. Gregorio-Jauregui, ${ }^{1}$ Ma. Guadalupe Pineda, ${ }^{1}$ Jorge E. Rivera-Salinas, ${ }^{1}$ Gil Hurtado, ${ }^{2}$ \\ Hened Saade, ${ }^{2}$ José L. Martinez, ${ }^{1}$ Anna Ilyina, ${ }^{1}$ and Raúl G. López ${ }^{2}$ \\ ${ }^{1}$ Departamento de Biotecnología, Facultad de Ciencias Químicas, Universidad Autónoma de Coahuila, \\ Boulevard V. Carranza y José Cárdenas Valdés, 25280 Saltillo, COAH, Mexico \\ ${ }^{2}$ Departamento de Procesos de Polimerización, Centro de Investigación en Química Aplicada, Boulevard Enrique Reyna No. 140, \\ 25294 Saltillo, COAH, Mexico \\ Correspondence should be addressed to Raúl G. López, glopez@ciqa.mx
}

Received 1 March 2012; Accepted 23 April 2012

Academic Editor: Sergio J. Mejía-Rosales

Copyright ( $) 2012$ Karla M. Gregorio-Jauregui et al. This is an open access article distributed under the Creative Commons Attribution License, which permits unrestricted use, distribution, and reproduction in any medium, provided the original work is properly cited.

\begin{abstract}
Preparation of magnetic nanoparticles coated with chitosan in one step by the coprecipitation method in the presence of different chitosan concentrations is reported here. Obtaining of magnetic superparamagnetic nanoparticles was confirmed by X-ray diffraction and magnetic measurements. Scanning transmission electron microscopy allowed to identify spheroidal nanoparticles with around $10-11 \mathrm{~nm}$ in average diameter. Characterization of the products by Fourier transform infrared spectroscopy demonstrated that composite chitosan-magnetic nanoparticles were obtained. Chitosan content in obtained nanocomposites was estimated by thermogravimetric analysis. The nanocomposites were tested in $\mathrm{Pb}^{2+}$ removal from a $\mathrm{PbCl}_{2}$ aqueous solution, showing a removal efficacy up to $53.6 \%$. This work provides a simple method for chitosan-coated nanoparticles obtaining, which could be useful for heavy metal ions removal from water.
\end{abstract}

\section{Introduction}

Magnetic iron oxides, like magnetite $\left(\mathrm{Fe}_{3} \mathrm{O}_{4}\right)$ and maghemite $\left(\gamma-\mathrm{Fe}_{2} \mathrm{O}_{3}\right)$ are a widely known materials because of their superparamagnetism when the particles are smaller enough [1]. This property, along their low toxicity and a great surface/area ratio, makes magnetic nanoparticles attractive for a number of actual and potential applications [2-8]. For applications in biomedical and environmental fields, magnetic nanoparticles are usually coated with polymers, bounded to the particle through organic linkers [9]. This type of coating is able to recognize specific molecules and ions for their binding and removal. Furthermore, in some cases it offers enhanced stability [10].

Chitosan is a partially deacetylated form of chitin obtained by thermochemical treatment. It has been identified as a versatile biopolymer, nontoxic, and biodegradable, which is used for a number of agriculture, food, and biopharmaceutical applications $[11,12]$. Free amino and hydroxyl groups are responsible for the reactivity of this polymer. Magnetic nanoparticles coated with chitosan can provide a convenient tool for exploring separation techniques as well as novel applications in fields such as protein and metal adsorption $[2,13,14]$.

Obtaining of magnetic nanoparticles coated with chitosan by coprecipitation of magnetic material followed by polymer coating is a well-documented method [13, 15-18]. Using this approach, chitosan-coated magnetic nanoparticles from 14 [17] to $25-30 \mathrm{~nm}[13,15,16]$ in average diameter and different coating degrees were obtained.

An attractive option to obtain this type of particles is carrying out precipitation and coating in one step. To our best knowledge, there are very few reports on this subject [19, 20]. Hong and Rhee [19] prepared chitosan-coated magnetic nanoparticles with $28 \mathrm{wt}$. \% in theoretical chitosan content by coprecipitation in a solution containing $\mathrm{Fe}^{+2}, \mathrm{Fe}^{+3}$, and chitosan. However, particle size as determined by quasielastic light dispersion was relatively large, $67 \mathrm{~nm}$ in average 
diameter, despite that uncoated magnetic nanoparticles were very small, with average diameter around $7.5 \mathrm{~nm}$. The cause of this increase in size was not discussed in the paper. Furthermore, additional characterization of coated nanoparticles was not included. Rather, the attention was focused on establishing the effect of chitosan-coated magnetic nanoparticles on the relaxation times of hydrogen protons of water molecules in a dispersion of this type of particles in water. On the other hand, $\mathrm{Wu}$ et al. [20] reported the in situ preparation of chitosan-coated magnetic nanoparticles for lipase immobilization. The nanoparticles were obtained by precipitation of $\mathrm{Fe}(\mathrm{OH})_{2}$ and further controlled oxidation to $\mathrm{Fe}_{3} \mathrm{O}_{4}$ in an aqueous solution containing crosslinked chitosan. It is noteworthy that the weight ratio chitosan in the formulation to the theoretical $\mathrm{Fe}_{3} \mathrm{O}_{4}$ was very high $(\approx 8.7)$. In contrast with the report of Hong and Rhee [19], $\mathrm{Wu}$ et al. [20], based on the characterization by vibrating sample magnetization and the thermogravimetric analysis of the nanoparticles, concluded that chitosan-coated magnetic nanoparticles were prepared. According to the measurements by transmission electron microscopy, particle diameters of $\mathrm{Fe}_{3} \mathrm{O}_{4}$ ranged between 10 and $20 \mathrm{~nm}$ and those of chitosancoated magnetic nanoparticles, between 50 and $100 \mathrm{~nm}$.

We report in this paper the coprecipitation of magnetic nanoparticles in the presence of different chitosan concentrations. A detailed characterization of the products was carried out to demonstrate the feasibility of this method for obtaining chitosan-coated magnetic nanoparticles in one step. Moreover, the kinetics of interaction between selected nanocomposites and $\mathrm{Pb}^{+2}$ ions was determined to evaluate their ability to ions removal.

\section{Materials and Methods}

2.1. Materials. All reagents were high-purity grades from Aldrich and used without further purification: chitosan with low molecular weight and 75\% deacetylation degree, ferric chloride $\left(\mathrm{FeCl}_{3} \cdot 6 \mathrm{H}_{2} \mathrm{O}, 99 \%\right)$, ferrous chloride $\left(\mathrm{FeCl}_{2} \cdot 4 \mathrm{H}_{2} \mathrm{O}\right.$, $98 \%$ ), and aqueous ammonia $\left(\mathrm{NH}_{4} \mathrm{OH}, 57.6\right.$ wt. \%). Deionized and triple-distilled water was drawn from a Millipore system.

2.2. Preparation of Coated Magnetic Nanoparticles. The process was carried out in a $150 \mathrm{~mL}$ jacketed glass reactor equipped with a reflux condenser, mechanical agitation (400 rpm), and an inlet for the feed of aqueous ammonia. All the reactions were performed in duplicate (set 1 and set 2 ). The procedure started with mixing in the reactor $50 \mathrm{~mL}$ of $\mathrm{FeCl}_{3} \cdot 6 \mathrm{H}_{2} \mathrm{O}(0.32 \mathrm{M})$ and $50 \mathrm{~mL}$ of $\mathrm{FeCl}_{2} \cdot 4 \mathrm{H}_{2} \mathrm{O}(0.2 \mathrm{M})$. Then, the required amount of chitosan was added to the reaction mixture, raising the mixture temperature to $50^{\circ} \mathrm{C}$. Three concentrations of chitosan were used: $0.125,0.25$, and $0.5 \%(\mathrm{w} / \mathrm{v})$. Coprecipitation reaction without chitosan was also carried out as a control. Once $\mathrm{Fe}^{+2}, \mathrm{Fe}^{+3}$, and chitosan solution reached the desired temperature $\left(50^{\circ} \mathrm{C}\right)$, the dosing of $20 \mathrm{~mL}$ of the aqueous ammonia at $0.67 \mathrm{~mL} / \mathrm{min}$ was started. After dosing was over, the completion reaction was allowed to proceed for $20 \mathrm{~min}$. At the end of the reaction, the particles were recovered by using a permanent magnet, washed 25 times with de-ionized water, and lyophilized to obtain the final product.

2.3. Nanocomposites Characterization. X-ray analysis of the products were carried out with a Siemens D-5000 diffractometer using $\mathrm{Cu}-\mathrm{K}_{\alpha}(\lambda=1.5418 \AA)$ as incident radiation. The size and morphology of the particles were determined in a JEOL JSM-7401F scanning-transmission electron microscope (STEM), for which samples were prepared by dispersing the resulting powders in water with ultrasonication and then depositing the dispersion on a copper grid. The magnetic properties of the nanoparticles were determined using a Physical Properties Measurement System from Quantum Design, model 6000 in mode-vibrating sample magnetometer (VSM), with an applied field between -20.0 to $20.0 \mathrm{kOe}$ at room temperature. Attenuated total reflectance (ATR) Fourier transform infrared spectrometry (FTIR) was carried out in a Magna IR 550 from Nicolet with germanium crystal. Thermogravimetric analysis (TGA) of nanocomposite and chitosan was performed in a TGA Q500 from TA Instruments. Analyzed samples were heated from 30 to $800^{\circ} \mathrm{C}$ at a heating rate of $10^{\circ} \mathrm{C} / \mathrm{min}$ under a nitrogen flow of $50 \mathrm{~mL} / \mathrm{min}$.

\section{4. $\mathrm{Pb}^{+2}$ Removal by Using Chitosan-Coated Magnetic Na-} noparticles. Typically, $60 \mathrm{mg}$ of dried nanoparticles were added to $50 \mathrm{~mL}$ of $10 \mathrm{ppm} \mathrm{Pb}^{+2}$ aqueous solution. Then, this mixture was ultrasonicated for $50 \mathrm{~min}$ at room temperature taking samples during the process each $10 \mathrm{~min}$. After the magnetic chitosan nanocomposites were removed, the concentration of $\mathrm{Pb}^{+2}$ in the samples was measured by atomic absorption spectroscopy in a Varian Spectra $250 \mathrm{AA}$ equipment.

\section{Results and Discussion}

All reactions rendered a black powder at the end of the process. There was no visually detected difference between the nanoparticles prepared with and without chitosan. Figure 1 shows the X-ray diffraction pattern (XRDP) of the final products obtained in set 1 of precipitation reactions. XRDP of the products from set 2 (not included) shows the same signals pattern. As is well-known, precipitation reactions from $\mathrm{Fe}^{+2}+\mathrm{Fe}^{+3}$ aqueous solution using aqueous ammonia usually produce a mixture of magnetite and maghemite. To compare with the obtained results, the standard patterns of these species, taken from the library of our X-ray equipment, were included in Figure 1. From this figure, it is evident that product patterns match pretty well those of maghemite and magnetite. Although differentiation between both species is not possible from the X-ray data in Figure 1, magnetite presence is evident due to the black color of the final products. It is noteworthy that there is no difference in the patterns of the products obtained with and without chitosan, which leads to conclude that the presence of this polymer does not affect the crystallinity of the precipitation reaction products.

The average grain sizes of the magnetic nanoparticles obtained in set 1 and 2 of precipitation reactions were 


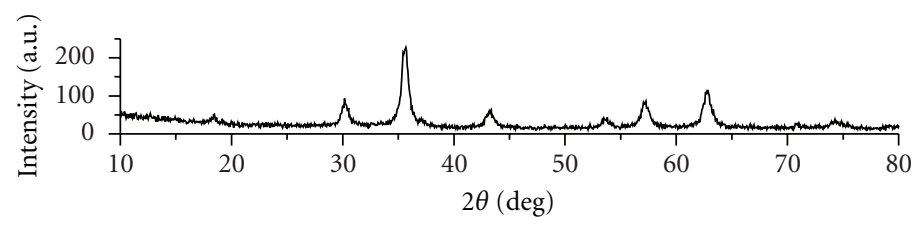

(a)

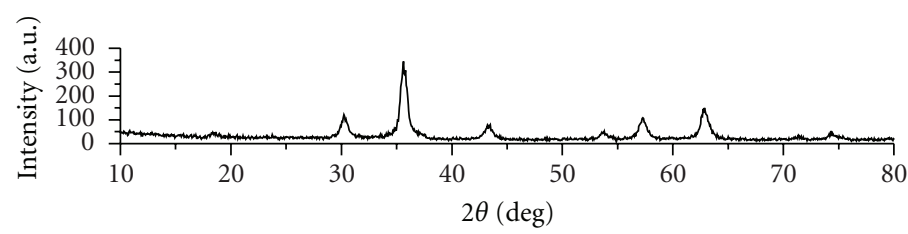

(b)

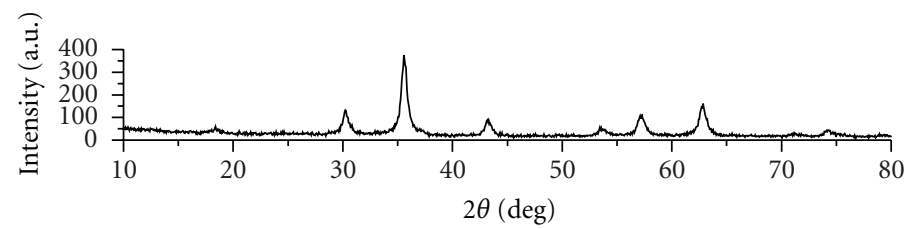

(c)

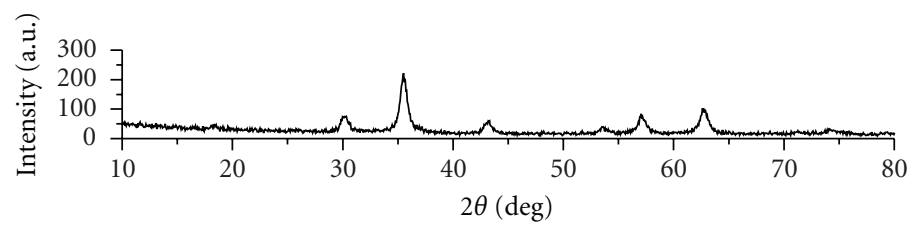

(d)

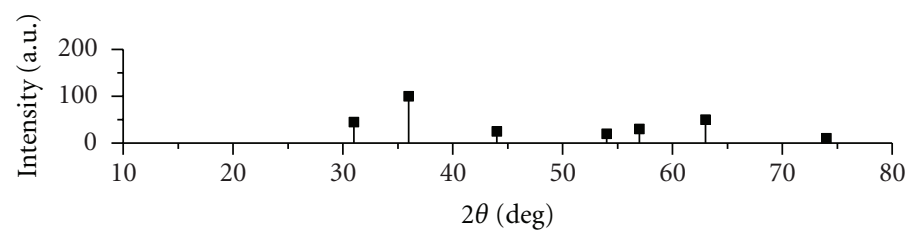

(e)

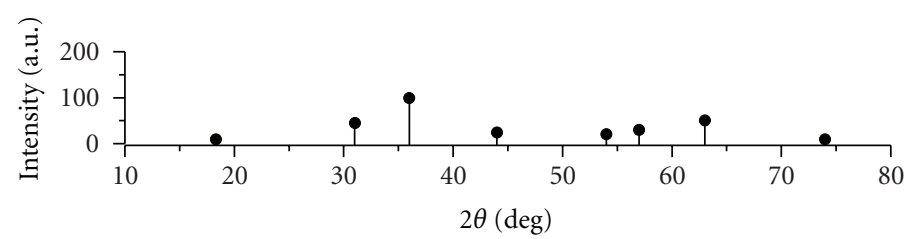

(f)

FIGURE 1: X-ray patterns of magnetic nanoparticles prepared by coprecipitation method (at $50^{\circ} \mathrm{C}$ ) without chitosan and with different chitosan concentrations: (a) without chitosan; (b) 0.125; (c) 0.25; (d) 0.5 (w/v \%); (e) magnetite standard pattern; (f) maghemite standard pattern.

calculated by using data from their XRDPs and the wellknown Scherrer equation, which is represented as

$$
d=\frac{K \lambda}{\beta \cos \theta},
$$

where $d$ is the average diameter of grain in nm; $K$ is the dimensional factor $(0.9) ; \lambda$ is the $\mathrm{X}$-ray wavelength $(0.154 \mathrm{~nm}) ; \beta$ is the line broadening at half the maximum intensity in radians and $\theta$ is the Bragg's angle. Calculated values of average diameter of grain were 11.1 $\pm 0.6,11.6 \pm$
$1.3,12.6 \pm 0.5$, and $10.6 \pm 0.3$ for products prepared with $0,0.125,0.25$, and $0.5 \%(\mathrm{w} / \mathrm{v})$ chitosan, respectively. These results indicate an absence of effect of chitosan on the grain size of magnetic nanoparticles.

Micrographs of the final products prepared with and without chitosan (set 1) are shown in Figure 2. Particles in this figure show a spheroidal morphology, but a difference between the particles obtained with and without chitosan is not evident. To characterize these particles, the sizes of more than 1000 of them were measured from different 

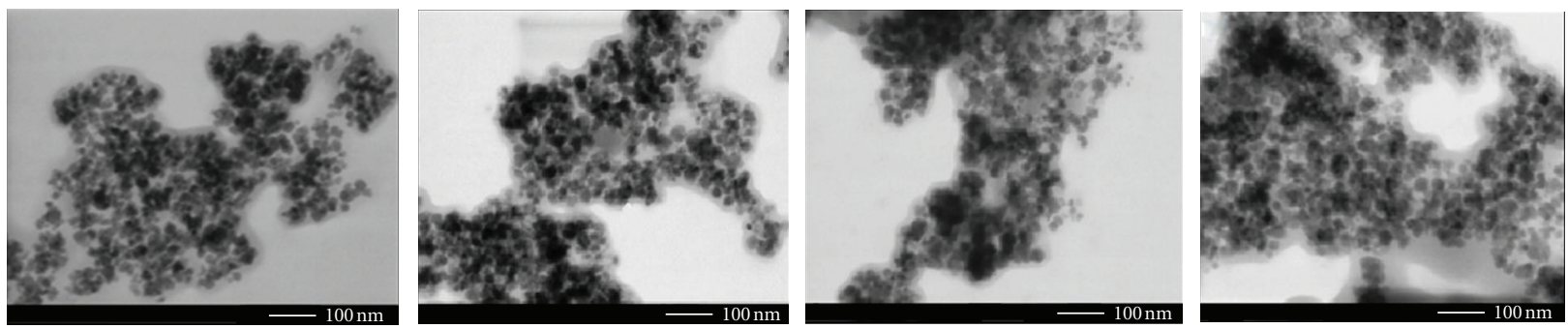

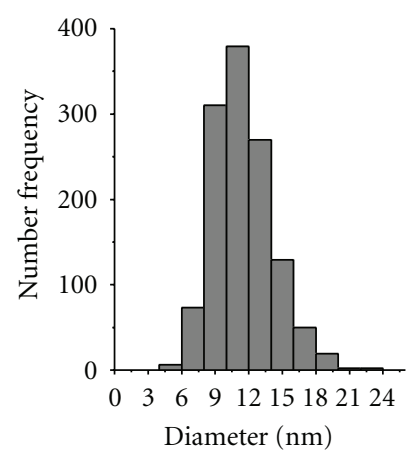

(a)

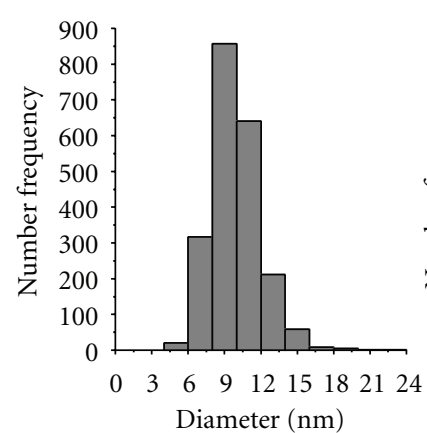

(b)

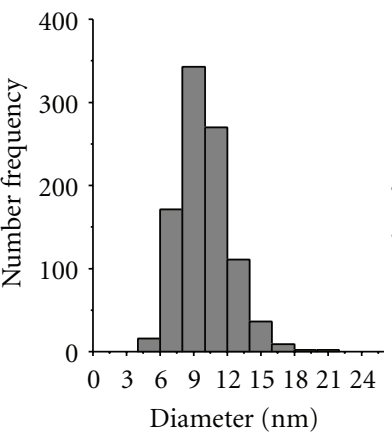

(c)

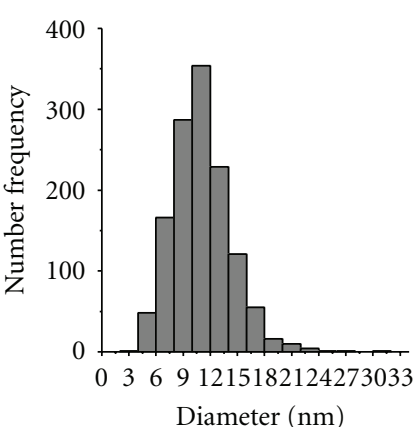

(d)

FIGURE 2: STEM micrographs and their corresponding particle diameter histograms of particles prepared by coprecipitation method (at $50^{\circ} \mathrm{C}$ ) without chitosan and with different chitosan concentrations: (a) without chitosan; (b) 0.125 ; (c) 0.25 ; (d) 0.5 (w/v \%).

micrographs of each of the samples using an image analysis program (ImageJ $1.37 \mathrm{c}$ ). The results of this analysis were presented as the corresponding histograms of particle diameters and included in Figure 2. Furthermore, the numberaverage diameter $\left(D_{n}\right)$, the weight-average diameter $\left(D_{w}\right)$, and the polydispersity index $\left(D_{w} / D_{n}\right)$ were calculated by using the following equations [21]:

$$
\begin{gathered}
D_{n}=\frac{\sum n_{i} D_{i}}{\sum n_{i}}, \\
D_{w}=\frac{\sum\left(n_{i} D_{i}\right)^{4}}{\sum\left(n_{i} D_{i}\right)^{3}},
\end{gathered}
$$

where $n_{i}$ is the number of particles of diameter $d_{i}$.

$D_{n}$ and polydispersity values from products (set 1) are shown in Table 1. It should be clarified that the data in this table correspond to the sizes of magnetic nanoparticles, that is, the nanoparticles without chitosan coating. As it can be seen, $D_{n}$ of magnetic nanoparticles obtained in this study when chitosan was used in their preparation ranges from 9.9 to $11 \mathrm{~nm}$, a very small range to consider that a direct relation between the particle size and the chitosan used in the formulation exists. It is noteworthy that these particle diameters are smaller than those reported in the preparation of magnetic nanoparticles by coprecipitation method, which ranges from 14 [17] to $25-30 \mathrm{~nm}[13,15,16]$. Although, it cannot be excluded that other authors using this method have obtained magnetic nanoparticles with similar sizes to those obtained in this work, they were not identified in the search in the specialized literature.
TABLE 1: Average diameters and polydispersity index of particles prepared by coprecipitation method determined: (a) from XRD data; (b) and (c) from STEM micrographs.

\begin{tabular}{lccc}
\hline $\begin{array}{l}\text { Chitosan content } \\
\text { in reaction mixture } \\
(\mathrm{w} / \mathrm{v} \%)\end{array}$ & $D_{p}{ }^{(\mathrm{a})}(\mathrm{nm})$ & $D_{n}{ }^{(\mathrm{b})}(\mathrm{nm})$ & $D_{w} / D_{n}{ }^{(\mathrm{c})}$ \\
\hline 0 & $11.1 \pm 0.6$ & 11.5 & 1.2 \\
0.125 & $11.6 \pm 1.3$ & 9.9 & 1.1 \\
0.250 & $12.6 \pm 0.5$ & 10.0 & 1.2 \\
0.500 & $10.6 \pm 0.3$ & 11.0 & 1.3 \\
\hline
\end{tabular}

For comparison, the values of grain average diameters calculated with Scherrer equation are also included in Table 1. Data in this table indicate that sizes from X-ray information and those measured by STEM are very similar. This suggests that no aggregation of the grains during magnetic nanoparticles forming was occurred, even in the presence of chitosan.

To this point, it is clear that a mixture of magnetitemaghemite nanoparticles was obtained in presence of chitosan. It is assumed that at least part of chitosan used in the process is coating these nanoparticles. This assumption comes from the expected bond between the hydroxyl groups in the chitosan and the oxygen atoms of $\mathrm{Fe}_{3} \mathrm{O}_{4}$ (magnetite) and $\mathrm{Fe}_{2} \mathrm{O}_{3}$ (maghemite). Unfortunately, it was not possible to demonstrate this assumption by STEM. Nevertheless, in the following, the obtaining of a composite chitosan-magnetic nanoparticles will be demonstrated. 
TABLE 2: Results of magnetic characterization of nanoparticles obtained at $50^{\circ} \mathrm{C}$ without chitosan and with different chitosan concentrations.

\begin{tabular}{lccc}
\hline $\begin{array}{l}\text { Chitosan content } \\
\text { in reaction mixture } \\
(\mathrm{w} / \mathrm{v} \%)\end{array}$ & $\begin{array}{c}\text { Magnetization at } 20 \mathrm{kOe} \\
(\mathrm{emu} / \mathrm{g})\end{array}$ & $\begin{array}{c}\text { Remnant magnetization } \\
(\mathrm{emu} / \mathrm{g})\end{array}$ & $\begin{array}{c}\text { Coercivity }(\mathrm{Oe}) \\
0\end{array}$ \\
\hline 0.125 & $60.13 \pm 0.01$ & $2.33 \pm 1.32$ & $26.85 \pm 13.62$ \\
0.250 & $66.35 \pm 2.10$ & $2.29 \pm 0.41$ & $27.09 \pm 4.24$ \\
0.500 & $45.07 \pm 3.73$ & $4.61 \pm 2.03$ & $64.39 \pm 41.98$ \\
\hline
\end{tabular}

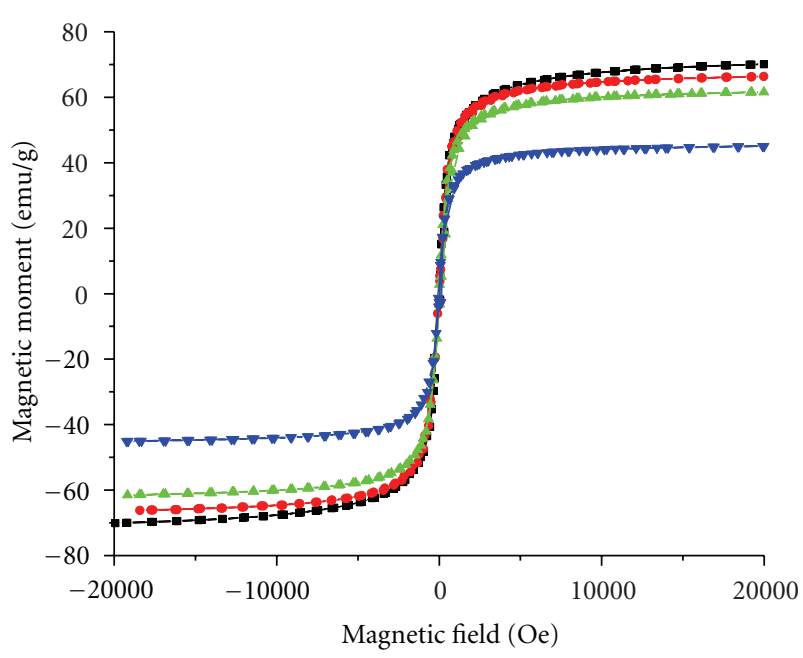

Figure 3: Magnetization curves determined at room temperature for particles prepared by coprecipitation method $\left(\right.$ at $\left.50^{\circ} \mathrm{C}\right)$ without chitosan and different chitosan concentrations: $(\mathbf{\square})$ without chitosan; $(\bullet)$ 0.125; ( $\mathbf{\Delta}) 0.25 ;(\boldsymbol{\nabla}) 0.5($ w/v \%) .

The results of magnetic measurements of the nanoparticles prepared in set 1 are depicted in Figure 3. None of the curves in this figure shows magnetic saturation up to $20 \mathrm{kOe}$, which is understandable taken into account that the surface atoms in very small particles, which constitute a great fraction of the total atoms, have difficulties for aligning the magnetic moments in the direction of applied magnetic field [22]. The results of magnetic characterization of nanoparticles from set 2 (not shown) are very similar to those described for nanoparticles from set 1 . Table 2 shows the mean values of the magnetic properties for the products obtained in precipitation reactions (set 1 and set 2 ).

Obtained results (Figure 3 and Table 2) demonstrate that nanoparticles prepared without chitosan are characterized by the highest final magnetization value $(70.1 \mathrm{emu} / \mathrm{g})$ and that this value decrease between 66.4 and $45.1 \mathrm{emu} / \mathrm{g}$, as chitosan content in the precipitation reactions increases. Furthermore, the very small values for remnant magnetization (2.3-4.6 emu/g) and coercivity field (26.9-64.4 Oe) suggest a superparamagnetic behavior of all the nanoparticles prepared in this study [23]. In fact, this behavior is typical of magnetite and maghemite nanoparticles smaller than $10-15 \mathrm{~nm}$ in diameter [23]. The decrease of the nanoparticles final magnetization as the chitosan content used in the precipitation reactions increased indicates that the proportion of the nonmagnetic material (in this case, chitosan) in nanoparticles increased. A comparison of the results of magnetic characterization obtained in this study with those reported in the specialized literature indicates that the final magnetization value of the naked particles prepared in this study is higher than those reported by Ge et al. [17] and $\mathrm{Wu}$ et al. [20]. Furthermore, they are similar to that obtained by Pan et al. [16] but lower than those reported by Liu et al. [13] and Kuo et al. [18], who obtained values of magnetic saturation around $80 \mathrm{emu} / \mathrm{g}$. Nevertheless, due to the relatively large size of the nanoparticles $(\approx 25 \mathrm{~nm}$ in average diameter) obtained by Liu et al., they presented a ferromagnetic behavior, which is not attractive for some applications where reuse of nanoparticles is required, because their high values of remnant magnetization. Regarding to chitosan-coated nanoparticles, the final magnetization values obtained in this study are similar to those reported by other authors [16-18] and higher than that reported by $\mathrm{Wu}$ et al. [20], who obtained a value of $35.5 \mathrm{emu} / \mathrm{g}$. It is noteworthy the relatively high values of final magnetization were obtained in this study, despite that the sizes of magnetic nanoparticles are in the bottom of the sizes range reported in the literature on preparation of magnetic nanoparticles by coprecipitation method [13, 15-20]. In accordance with the known fact that the magnetization of small particles (diameters smaller than ca. $15 \mathrm{~nm}$ ) decreases as particle size decreases [24, 25], smaller values of magnetization should be expected. Based on the reported direct relation between crystallinity and magnetization in magnetic particles [26], the higher magnetization values obtained in this study could be tentatively ascribed to an improved crystallinity of the magnetic nanoparticles.

Conclusive evidence of the obtaining of chitosan-coated magnetic nanoparticles in this study arose from FTIR results (Figure 4). This figure includes the IR spectra for all the prepared nanoparticles (set 1). In accordance with Figure 4, the characteristic absorption bands for chitosan appeared at $3363(\mathrm{O}-\mathrm{H}$ and $\mathrm{N}-\mathrm{H}$ stretching vibrations), 2874 (C-H stretching vibrations), 1653 ( $\mathrm{N}-\mathrm{H}$ bending vibrations), and $1070 \mathrm{~cm}^{-1}$ (C-O-C stretching vibrations) [27, 28]. The spectra of the products obtained using chitosan show the four characteristic absorption bands for this polymer. Taken into account that the products of the reactions were exhaustively washed and magnetically recovered, it was concluded that all the chitosan in the final products are chemically bound to the magnetic nanoparticles. Results of FTIR demonstrated that the precipitation reactions carried out with chitosan led to obtain a composite chitosan-magnetic nanoparticles. 
TABLE 3: Immobilization of chitosan on the nanoparticles obtained by coprecipitation method at $50^{\circ} \mathrm{C}$.

\begin{tabular}{lcc}
\hline $\begin{array}{l}\text { Chitosan content } \\
\text { in reaction mixture } \\
(\mathrm{w} / \mathrm{v} \%)\end{array}$ & $\begin{array}{c}\text { Theoretical immobilized chitosan on the } \\
\text { nanoparticles } \\
(\mathrm{mg} / \mathrm{g})\end{array}$ & $\begin{array}{c}\text { Immobilized chitosan on the } \\
\text { nanoparticles }^{\mathrm{b}} \\
(\mathrm{mg} / \mathrm{g})\end{array}$ \\
\hline 0.125 & 60.67 & 135.85 \\
0.250 & 121.58 & 148.5 \\
0.500 & 243.00 & 584.79 \\
\hline
\end{tabular}

${ }^{a}$ Calculated from the recipe of precipitation reactions.

${ }^{\mathrm{b}}$ Estimated from TGA results.

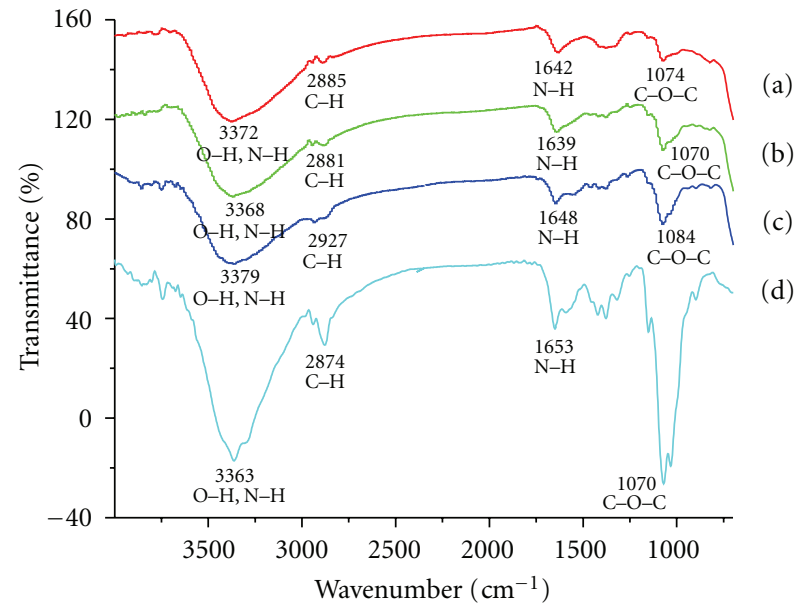

FIGURE 4: FTIR spectra of particles prepared by coprecipitation method (at $50^{\circ} \mathrm{C}$ ) with different chitosan concentrations: (a) 0.125 ; (b) 0.25 ; (c) $0.5(\mathrm{w} / \mathrm{v} \%$ ); (d) pure chitosan FTIR spectra.

The results of characterization by TGA of the products obtained in set 1 (Figure 5) were used for the estimation of the amount of chitosan immobilized on the nanoparticles. As it can be seen in this figure, the product prepared without chitosan, that is, the mixture magnetite-maghemite, showed $2.16 \%$ in weight loss when it was heated from 30 to $800^{\circ} \mathrm{C}$. Pan et al. [16] reported that a sample of $\mathrm{Fe}_{3} \mathrm{O}_{4}$ lost 1.3 wt. \% when it was heated from 30 to $300^{\circ} \mathrm{C}$ in a TGA equipment under similar conditions to those used in this study. As indicated by Pan et al. [16], this weight loss can be ascribed to the removal of free and chemically adsorbed water. On the other hand, a sample of pure chitosan, whose thermogram was also included in Figure 5, showed a weight loss of $69.4 \%$. As it was expected, the composites showed weight losses intermediate between those of the mixture magnetite-maghemite and pure chitosan: 10 , 11 , and $27 \%$ for the products prepared with $0.125,0.25$, and $0.5 \%(\mathrm{w} / \mathrm{v})$, respectively. Using these results and the weight of the samples before and after TGA characterization, the quantities of chitosan immobilized on the nanoparticles were estimated (Table 3). For comparison, the theoretical values of immobilized chitosan calculated from the recipe of precipitation reactions, assuming that the reactions proceeded to $100 \%$ and only magnetite was obtained, were also included in Table 3. In accordance with the data in this table, the amounts of chitosan immobilized on the nanoparticles

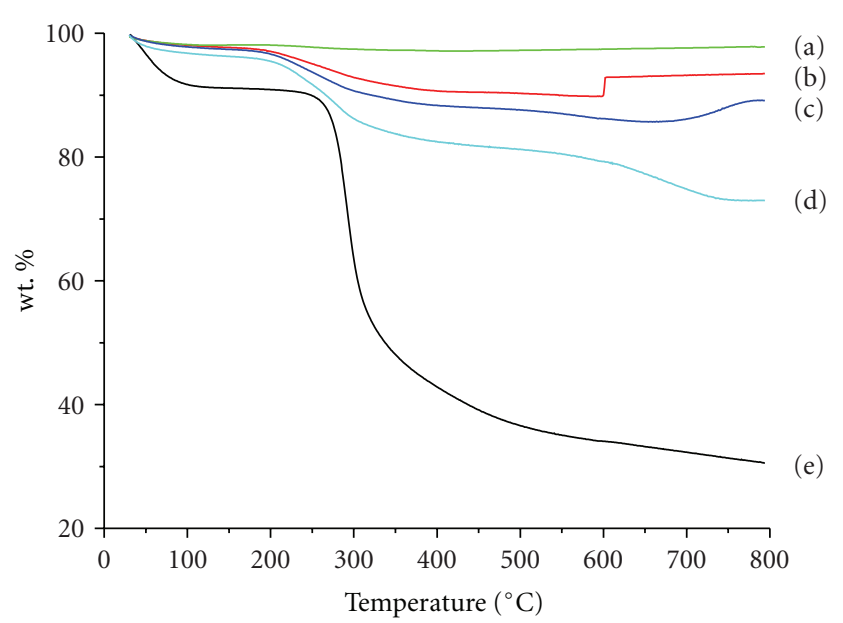

Figure 5: Thermal degradation curves of particles prepared by coprecipitation method (at $50^{\circ} \mathrm{C}$ ) without chitosan and with different chitosan concentrations: (a) without chitosan; (b) 0.125 ; (c) 0.25 ; (d) $0.5(\mathrm{w} / \mathrm{v} \%)$; (e) pure chitosan thermal degradation curve.

estimated from TGA measurements were consistently higher than the theoretical values. This difference can be explained if the precipitation reactions do not proceed to $100 \%$, which would lead to increase the chitosan/nanoparticles ratio.

Having demonstrated the preparation of magnetic nanoparticles with average diameters around 10-11 nm covered with chitosan in one step, the final test in this study was to evaluate the efficacy of the obtained composites in $\mathrm{Pb}^{+2}$ removal from a $\mathrm{Pb}\left(\mathrm{NO}_{3}\right)_{2}$ aqueous solution. This test is based on the ability of chitosan to chelate heavy metal ions through its amino groups. For this, the composites prepared with 0.125 and $0.5 \%(\mathrm{w} / \mathrm{v})$ chitosan in set 1 were evaluated. Figure 6 shows that the $\mathrm{Pb}^{+2}$ concentration drops from its initial value $(10 \mathrm{ppm})$ to around 6.2 in the first 10 minutes in the assay when the composite was prepared with $0.125 \%(\mathrm{w} / \mathrm{v})$ chitosan. Then, it slowly decreases to attain a final value of $4.6 \mathrm{ppm}$ at the end of the test. In the assay carried out with the composite prepared with $0.5 \%(\mathrm{w} / \mathrm{v})$ chitosan, values of 8.3 and $6.0 \mathrm{ppm}$ were attained in the first 10 minutes and at the end of the assay, respectively. From here, a removal efficacy of $53.6 \%$ for the chitosancoated magnetic nanoparticles prepared with $0.125 \%(\mathrm{w} / \mathrm{v})$ chitosan and of $39.8 \%$ for those prepared with $0.5 \%(\mathrm{w} / \mathrm{v})$ were calculated, which is surprising, because of a direct 


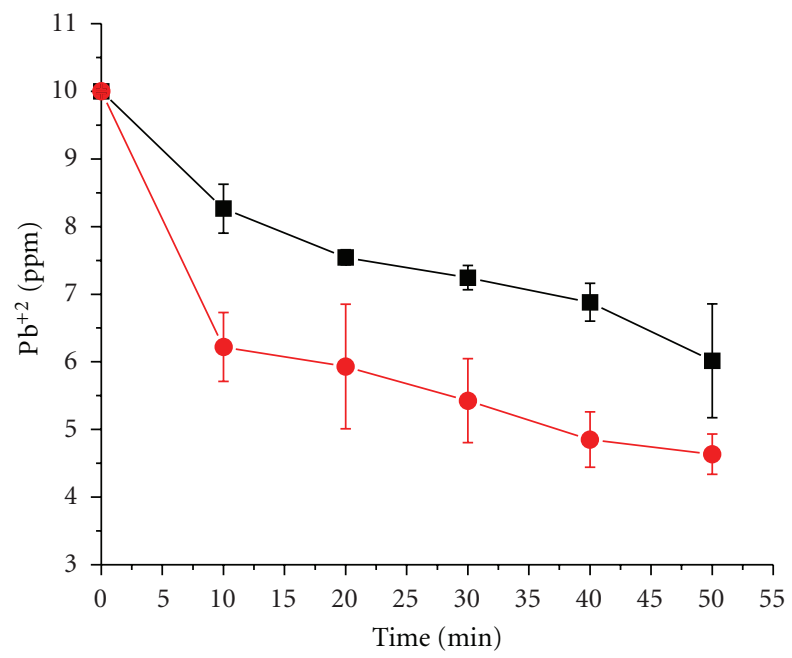

FIGURE 6: $\mathrm{Pb}^{+2}$ removal as a function of time using chitosan-coated magnetic nanoparticles prepared with $(\bullet) 0.125$ and $(\boldsymbol{\square}) 0.5 \%(\mathrm{w} / \mathrm{v})$ chitosan.

relation between removal efficacy and chitosan content in the evaluated composites was expected. This indicates that the nanoparticles prepared with the higher chitosan content have a smaller total amount of amino groups on their surface, which really means that they have less total surface area than the nanoparticles prepared with $0.125 \%$ (w/v) chitosan. A possible explanation for this behavior is that contents of chitosan as higher as $0.5 \%(\mathrm{w} / \mathrm{v})$, under the conditions used in this study, favor the aggregation of chitosan-coated nanoparticles. In turn, this would lead to an increase in the final nanocomposite size and, as a consequence, to a decrease in the total surface area.

Finally it should highlight the difference between the productivity in this study and those in the other reports on preparation of chitosan-coated magnetic nanoparticles in one step $[19,20]$. Calculations based on the formulations in the reports of Hong and Rhee [19] and Wu et al. [20] indicate theoretical productivities of around $0.1 \mathrm{~g}$ of magnetic nanoparticles per $100 \mathrm{~g}$ of reaction mixture. In contrast, theoretical productivity in this study is around $1.7 \mathrm{~g}$ per $100 \mathrm{~g}$ of reaction mixture. Furthermore, the weight ratio chitosan in the formulation/theoretical magnetic nanoparticles is close to 0.4 and 8.7 in the reports of Hong and Rhee and $\mathrm{Wu}$ et al., respectively. These values are higher than those calculated in this study, which range from 0.06 to 0.24 , depending on the used formulation. The highlighted differences indicate that the preparation of chitosan-coated magnetic nanoparticles in one step is a method able to attain relatively high productivities. Also, they suggest that an optimal ratio chitosan/magnetic nanoparticles should exist, which would lead to a minimization of particle aggregation.

\section{Conclusions}

A one-step method comprising the coprecipitation of magnetic nanoparticles in the presence of different chitosan concentrations allowed to obtain chitosan-coated magnetic nanoparticles with average diameter around $10-11 \mathrm{~nm}$, as demonstrated by X-ray diffraction, magnetic measurements, STEM, and FTIR. The ratios chitosan/magnetic nanoparticles were estimated, from the results of TGA, between 135.9 and $584.8 \mathrm{mg} / \mathrm{g}$. When evaluated for $\mathrm{Pb}^{+2}$ ions removal from a $\mathrm{Pb}\left(\mathrm{NO}_{3}\right)_{2}$ aqueous solution, chitosan-coated magnetic nanoparticles showed up to $53.6 \%$ in removal efficacy. This value corresponds to the composites with the lower chitosan content. It is believed that particle aggregation and, as a consequence, a decrease in the total surface area was favored when a higher chitosan content was used during the magnetic nanoparticles precipitation.

\section{Acknowledgments}

National Council of Science and Technology (CONACyT) supported this research through Grant 2007-84009. The authors are grateful to Jesús A. Cepeda, Alejandro Espinoza, and Blanca Huerta for their technical assistance in characterization work.

\section{References}

[1] S. J. Schneider, Engineered Materials Handbook: Ceramics and Glasses, ASM International, Materials Park, Ohio, USA, 1991.

[2] L. Zhu, J. Ma, N. Jia, Y. Zhao, and H. Shen, "Chitosan-coated magnetic nanoparticles as carriers of 5- fluorouracil: preparation, characterization and cytotoxicity studies," Colloids and Surfaces B, vol. 68, no. 1, pp. 1-6, 2009.

[3] T. Osaka, T. Matsunaga, T. Nakanishi, A. Arakaki, D. Niwa, and H. Iida, "Synthesis of magnetic nanoparticles and their application to bioassays," Analytical and Bioanalytical Chemistry, vol. 384, no. 3, pp. 593-600, 2006.

[4] S. Wan, J. Huang, H. Yan, and K. Liu, "Size-controlled preparation of magnetite nanoparticles in the presence of graft copolymers," Journal of Materials Chemistry, vol. 16, no. 3, pp. 298-303, 2006.

[5] K. Naka, A. Narita, H. Tanaka et al., "Biomedical applications of imidazolium cation-modified iron oxide nanoparticles," Polymers for Advanced Technologies, vol. 19, no. 10, pp. 14211429, 2008.

[6] A. G. Roca, R. Costo, A. F. Rebolledo et al., "Progress in the preparation of magnetic nanoparticles for applications in biomedicine," Journal of Physics D, vol. 42, no. 22, Article ID 224002, 2009.

[7] C. C. Berry, "Progress in functionalization of magnetic nanoparticles for applications in biomedicine," Journal of Physics D, vol. 42, no. 22, Article ID 224003, 2009.

[8] Q. A. Pankhurst, N. K. T. Thanh, S. K. Jones, and J. Dobson, "Progress in applications of magnetic nanoparticles in biomedicine," Journal of Physics D, vol. 42, no. 22, Article ID 224001, 2009.

[9] P. Li, A. M. Zhu, Q. L. Liu, and Q. G. Zhang, " $\mathrm{Fe}_{3} \mathrm{O}_{4} /$ poly(Nisopropylacrylamide)/chitosan composite microspheres with multiresponsive properties," Industrial and Engineering Chemistry Research, vol. 47, no. 20, pp. 7700-7706, 2008.

[10] V. Kekkonen, N. Lafreniere, M. Ebara, A. Saito, Y. Sawa, and R. Narain, "Synthesis and characterization of biocompatible magnetic glyconanoparticles," Journal of Magnetism and Magnetic Materials, vol. 321, no. 10, pp. 1393-1396, 2009. 
[11] V. Maghsoodi, J. Razavi, and S. Yaghmaei, "Production of chitosan by submerged fermentation from Aspergillus niger," Scientia Iranica, vol. 16, no. 2, pp. 145-148, 2009.

[12] Y. Zhuo, P. X. Yuan, R. Yuan, Y. Q. Chai, and C. L. Hong, "Bienzyme functionalized three-layer composite magnetic nanoparticles for electrochemical immunosensors," Biomaterials, vol. 30, no. 12, pp. 2284-2290, 2009.

[13] X. Liu, Q. Hu, Z. Fang, X. Zhang, and B. Zhang, "Magnetic chitosan nanocomposites: a useful recyclable tool for heavy metal ion removal," Langmuir, vol. 25, no. 1, pp. 3-8, 2009.

[14] Y. T. Zhou, H. L. Nie, C. Branford-White, Z. Y. He, and L. M. $\mathrm{Zhu}$, "Removal of $\mathrm{Cu}^{2+}$ from aqueous solution by chitosancoated magnetic nanoparticles modified with $\alpha$-ketoglutaric acid," Journal of Colloid and Interface Science, vol. 330, no. 1, pp. 29-37, 2009.

[15] D. T. K. Dung, T. H. Hai, L. H. Phuc, B. D. Long, L. K. Vinh, and P. N. Truc, "Preparation and characterization of magnetic nanoparticles with chitosan coating," Journal of Physics: Conference Series, vol. 187, no. 1, Article ID 012036, 2009.

[16] C. Pan, B. Hu, W. Li, Y. Sun, H. Ye, and X. Zeng, "Novel and efficient method for immobilization and stabilization of $\beta$-dgalactosidase by covalent attachment onto magnetic $\mathrm{Fe}_{3} \mathrm{O}_{4}$ chitosan nanoparticles," Journal of Molecular Catalysis B, vol. 61, no. 3-4, pp. 208-215, 2009.

[17] Y. Ge, Y. Zhang, S. He, F. Nie, G. Teng, and N. Gu, "Fluorescence modified chitosan-coated magnetic nanoparticles for high-efficient cellular imaging," Nanoscale Research Letters, vol. 4, no. 4, pp. 287-295, 2009.

[18] C. Kuo, Y. Liu, C. Liu et al., "Optimum conditions for lipase immobilization on chitosan coated $\mathrm{Fe}_{3} \mathrm{O}_{4}$ nanoparticles," Carbohydrate Polymers, vol. 87, no. 4, pp. 2538-2545, 2012.

[19] S. Hong and I. Rhee, "Relaxivity of hydrogen protons of water molecules in the aqueous solutions of dextran and chitosan coated ferrite nanoparticles," International Journal of Magnetic Resonance Imaging, vol. 1, no. 1, pp. 15-20, 2007.

[20] Y. Wu, Y. Wang, G. Luo, and Y. Dai, "In situ preparation of magnetic $\mathrm{Fe}_{3} \mathrm{O}_{4}$-chitosan nanoparticles for lipase immobilization by cross-linking and oxidation in aqueous solution," Bioresource Technology, vol. 100, no. 14, pp. 3459-3464, 2009.

[21] E. A. Collins, Emulsion Polymerization and Emulsion Polymers, John Wiley \& Sons, Chichester, UK, 1997.

[22] R. H. Kodama, "Magnetic nanoparticles," Journal of Magnetism and Magnetic Materials, vol. 200, no. 1, pp. 359-372, 1999.

[23] R.M. Cornell and U. Schwertmann, The Iron Oxides: Structure, Properties, Reactions, Occurrence and Uses, Wiley-VCH, Weinheim, Germany, 1996.

[24] L. Liz, M. A. López Quintela, J. Mira, and J. Rivas, "Preparation of colloidal $\mathrm{Fe}_{3} \mathrm{O}_{4}$ ultrafine particles in microemulsions," Journal of Materials Science, vol. 29, no. 14, pp. 3797-3801, 1994.

[25] S. Santra, R. Tapec, N. Theodoropoulou, J. Dobson, A. Hebard, and W. Tan, "Synthesis and characterization of silicacoated iron oxide nanoparticles in microemulsion: the effect of nonionic surfactants," Langmuir, vol. 17, no. 10, pp. 29002906, 2001.

[26] H. Qi, J. Ye, N. Tao, M. Wen, and Q. Chen, "Synthesis of octahedral magnetite microcrystals with high crystallinity and low coercive field," Journal of Crystal Growth, vol. 311, no. 2, pp. 394-398, 2009.

[27] L. Guo, G. Liu, R. Y. Hong, and H. Z. Li, "Preparation and characterization of chitosan poly(acrylic acid) magnetic microspheres," Marine Drugs, vol. 8, no. 7, pp. 2212-2222, 2010.
[28] L. Chen, C. Y. Tang, N. Y. Ning, C. Y. Wang, Q. Fu, and Q. Zhang, "Preparation and properties of chitosan/lignin composite films," Chinese Journal of Polymer Science, vol. 27, no. 5, pp. 739-746, 2009. 

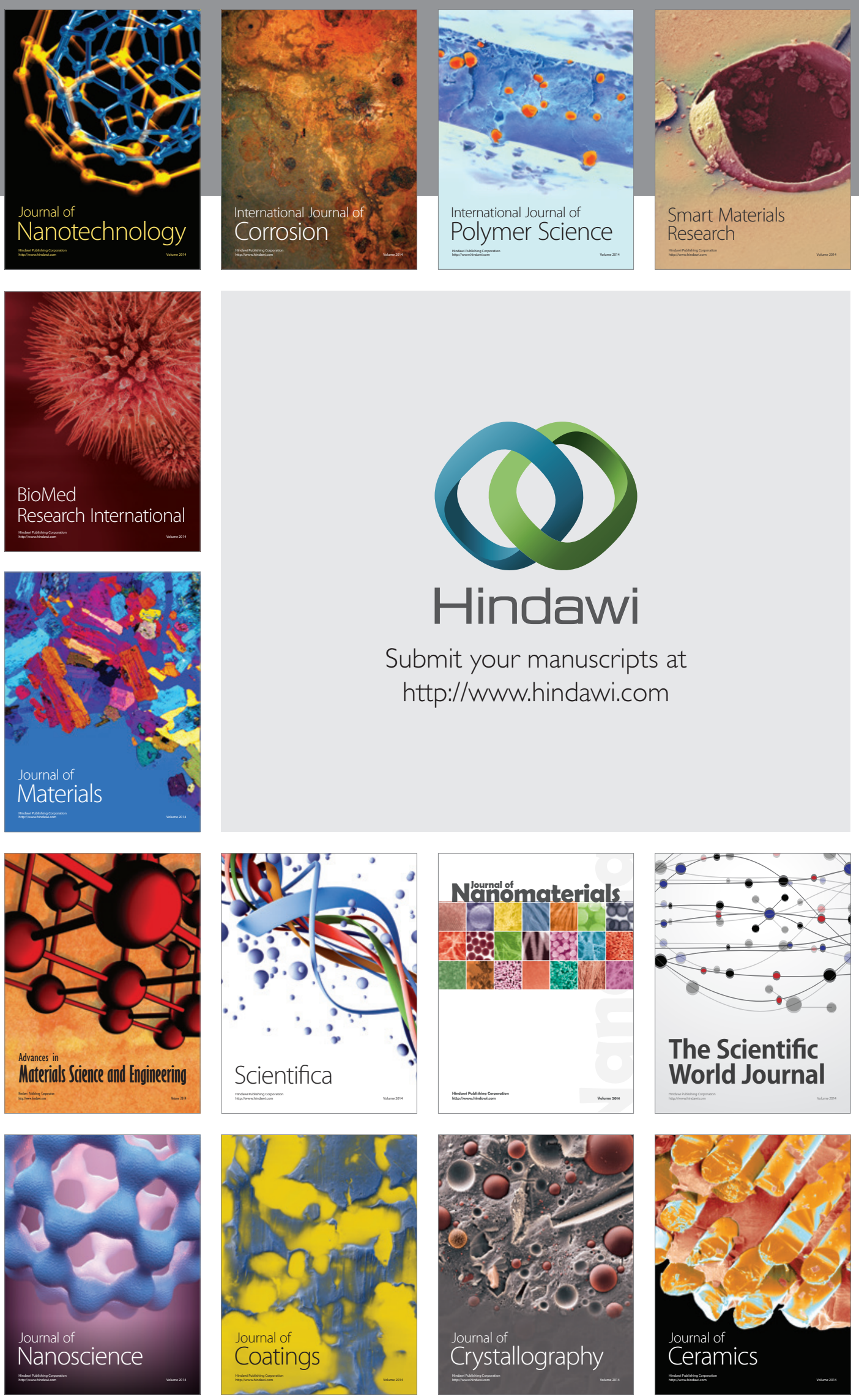

The Scientific World Journal

Submit your manuscripts at

http://www.hindawi.com

\section{World Journal}

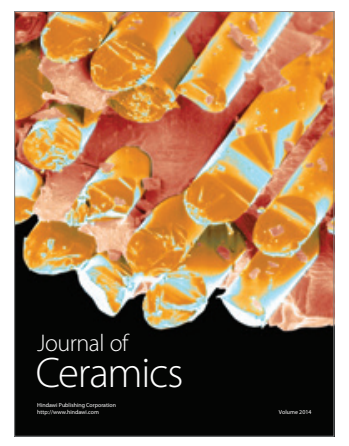

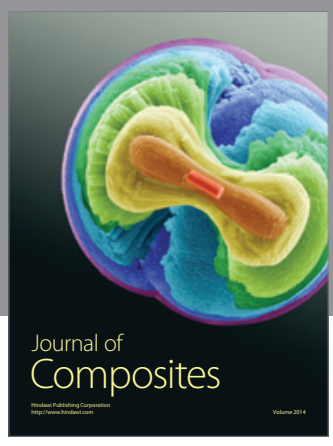
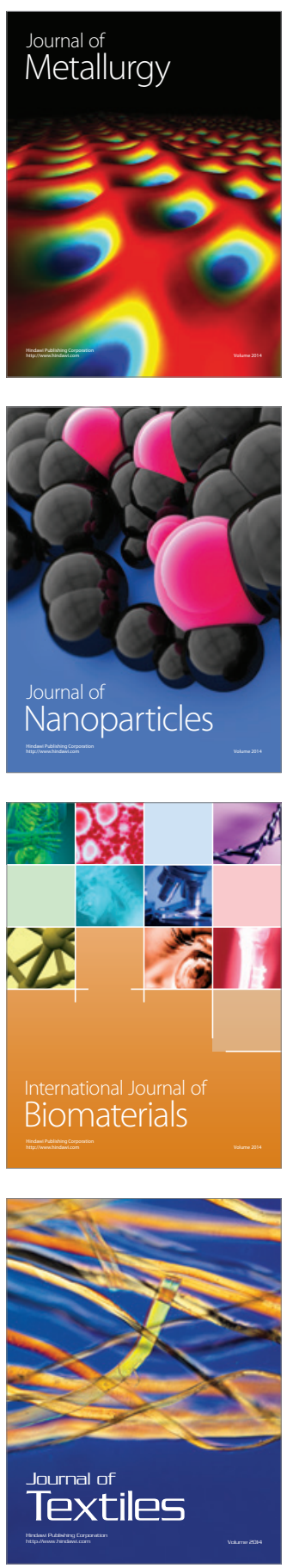